\title{
Renal parenchymal volume during and after acute pyelonephritis measured by ultrasonography
}

\author{
B JOHANSSON, ${ }^{*} S$ TROELL, $\dagger$ AND U BERG* \\ ${ }^{*}$ Departments of Paediatrics and †Diagnostic Radiology, Huddinge University Hospital, Huddinge, Sweden
}

SUMMARY A total of 47 children with acute pyelonephritis were investigated using water delay ultrasonographic equipment (Octoson) for determination of renal parenchymal volume by the stepped section technique. Thirty two patients were repeatedly investigated every to every other week up to seven weeks. Median renal parenchymal volume during acute pyelonephritis of the right kidney was $2.70 \mathrm{~cm}^{3} / \mathrm{kg}$ body weight and of the left kidney $3.10 \mathrm{~cm}^{3} / \mathrm{kg}$; this was significantly larger than the volume of control kidneys, which was 1.82 and $2.07 \mathrm{~cm}^{3} / \mathrm{kg}$, respectively. The most enlarged kidneys were found among the youngest children. A significant successive decrease in renal size was found during the first four to five weeks after the acute pyelonephritis.

Because of enlargement of the kidneys during acute pyelonephritis we suggest that the first renal size determination to be used for following renal growth should be performed after at least four to six weeks.

Three per cent of all girls will contract a symptomatic urinary tract infection before the age of $11 .{ }^{1}$ Half of them will have recurrent infections and $4 \cdot 5-13 \%$ will develop renal scarring, with or without concomitant vesicoureteric reflux. ${ }^{12}$ Cessation of renal growth after upper urinary tract infection-that is, acute pyelonephritis - has also been described. ${ }^{3-6}$ Consequently most children in Sweden have, so far, been investigated radiologically employing urography and micturition cystography after their first infection of acute pyelonephritis. Follow up urography has been performed about two years later to determine renal growth and to detect possible renal scarring. Renal scarring can also be detected by scanning with technetium labelled dimercaptosuccinic acid ( ${ }^{99 \mathrm{~m}}$ Tc DMSA). ${ }^{7}$

Renal enlargement has been described in adults with acute severe suppurative pyelonephritis, ${ }^{8-11}$ while in children with even less severe acute pyelonephritis renal enlargement seems to occur more often. ${ }^{12}{ }^{13}$ Renal size had decreased about two months after the acute infection. ${ }^{12}$ The exact time for the regression of this enlargement has not been clarified. It is now possible to perform repeated ultrasonographic investigations at short intervals and thereby determine more precisely the point in time of this regression.

The aim of the present investigation was to determine accurately the renal parenchymal volume by ultrasonography during the acute phase of the pyelonephritic infection and to follow up the change in renal parenchymal volume in children. We considered it essential to determine the time at which the renal enlargement had regressed in order to find the optimal time for the first examination of renal size after acute pyelonephritis. If this examination is performed too early the kidneys are still enlarged. The overestimation of renal size during the acute infection might later lead to an erroneous interpretation of retarded renal growth at the second renal size determination.

\section{Patients and methods}

A total of 47 children, aged $0 \cdot 4-15 \cdot 4$ years (median $4 \cdot 3$ ), were investigated. They all fulfilled the essential criteria for acute pyelonephritis as established by Jodal et al. ${ }^{14}$ All children had symptoms of fever with a temperature of more than $38.5^{\circ} \mathrm{C}$, a raised erythrocyte sedimentation rate of $>20 \mathrm{~mm}$ in the first hour or a raised $C$ reactive protein concentration $(>10 \mathrm{mg} / \mathrm{l})$, or both, as well as leucocyturia and positive urine cultures with a bacterial count of $>100000 / \mathrm{ml}$ of a single species or $>1000 / \mathrm{ml}$ in urine from suprapubic aspiration. All children were admitted to hospital and antibacterial treatment was started immediately after blood and urine specimens had been taken. The first ultrasonographic examina- 
tion was performed in all 47 children within the first week of admission. It was intended that the ultrasonography be repeated every to every other week up to about seven weeks. Some patients could not come to the hospital so often, some parents refused to come, and we also experienced technical faults with the ultrasonographic equipment; this resulted in 32 children being investigated two to five times (mean three) during the first seven weeks.

The ultrasonographic examination was carried out with automated water delay ultrasonographic equipment, the Octoson (Ausonics Ltd), and the renal parenchymal volume was determined by the stepped section method with longitudinal scans taken at 0.5 cm intervals. ${ }^{15}$ The volume of the renal parenchyma was calculated on the basis of the parenchymal areas of each scan multiplied by the thickness of the scans. To be able to compare renal sizes of children of differe int ages we have related our values to body weight. ${ }^{16}$

The method of measuring renal parenchymal volume had a methodological error of $0 \cdot 16 \mathrm{~cm}^{3} / \mathrm{kg}$ for the right kidney and $0 \cdot 14 \mathrm{~cm}^{3} / \mathrm{kg}$ for the left kidney. Kidneys showing a change in renal parenchymal volume $>0.3 \mathrm{~cm}^{3} / \mathrm{kg}$ between the acute examination and that performed after three to six weeks were considered to be affected by the infection.
Mann-Whitney's test and the paired $t$ test were used for statistical analysis. Results of 43 control subjects from a previous study were used for comparison. ${ }^{16}$

\section{Results}

Fig 1 shows one girl who first presented with a lower urinary tract infection after which she was investigated ultrasonographically. Two days later she became ill with acute pyelonephritis and new ultrasonography was done. The renal parenchymal volume of the left kidney increased from $43 \mathrm{~cm}^{3}$ to $59 \mathrm{~cm}^{3}(137 \%$ of initial volume) and the right from $49 \mathrm{~cm}^{3}$ to $67 \mathrm{~cm}^{3}(137 \%)$. The enlargement seems to have remained unchanged for a week, after which a gradual decrease in size was seen, reaching the initial value about four weeks later.

Fig 2 shows the renal parenchymal volume of the right and left kidney during the acute phase of acute pyelonephritis and the corresponding parenchymal volumes in the control series. ${ }^{16}$ As it is clinically impossible to know whether acute pyelonephritis is unilateral or bilateral, especially in small children, we have decided to show the sizes of all kidneys irrespective of whether they are infected or not. The median renal parenchymal volumes of the right and left kidney at infection were $2 \cdot 70$ and $3 \cdot 10 \mathrm{~cm}^{3} / \mathrm{kg}$

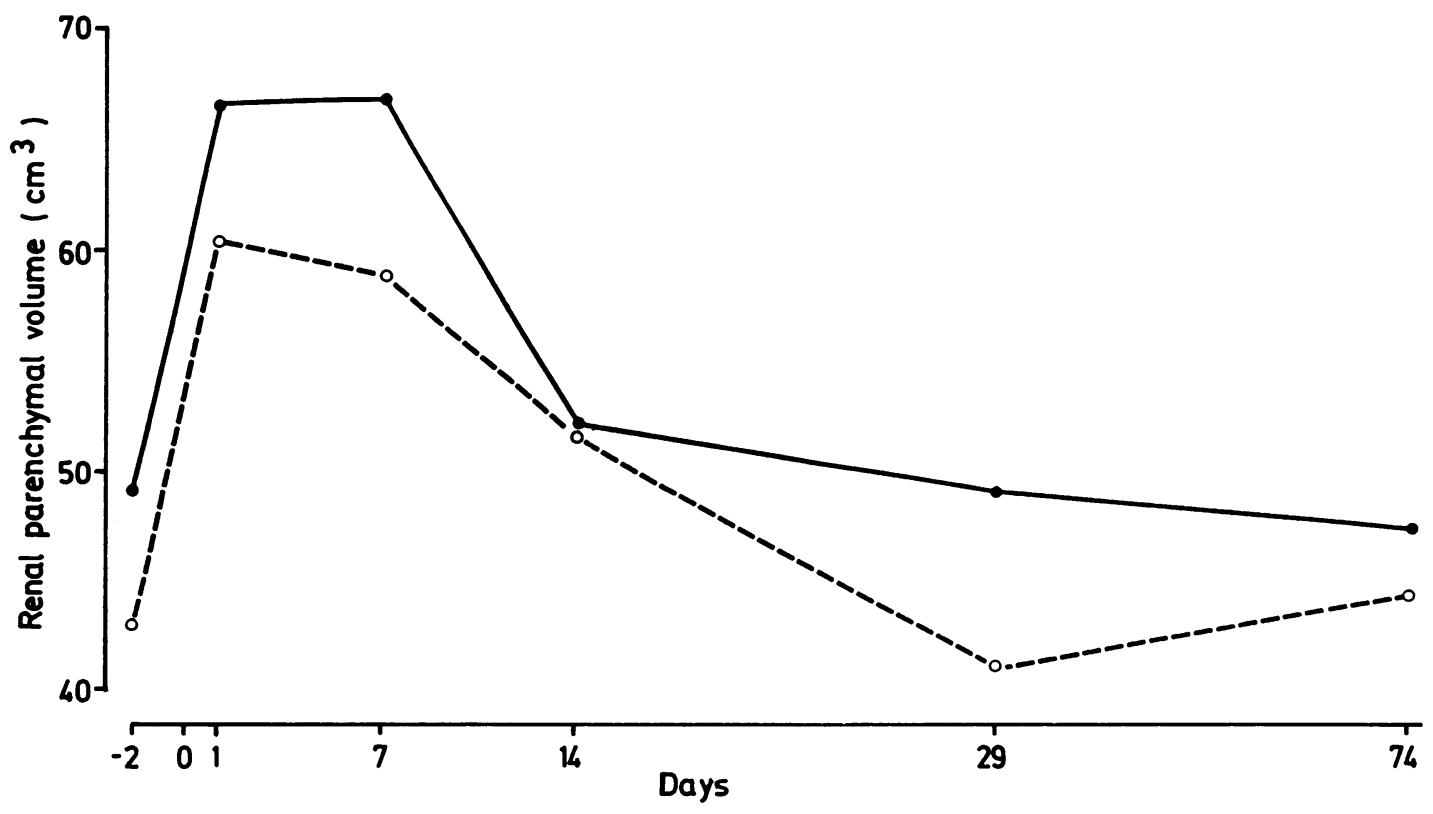

Fig 1 Renal parenchymal volume of the right (unbroken line) and left (broken line) kidney of a girl examined two days before and at one, seven, 14, 29, and 74 days after acute pyelonephritis. 


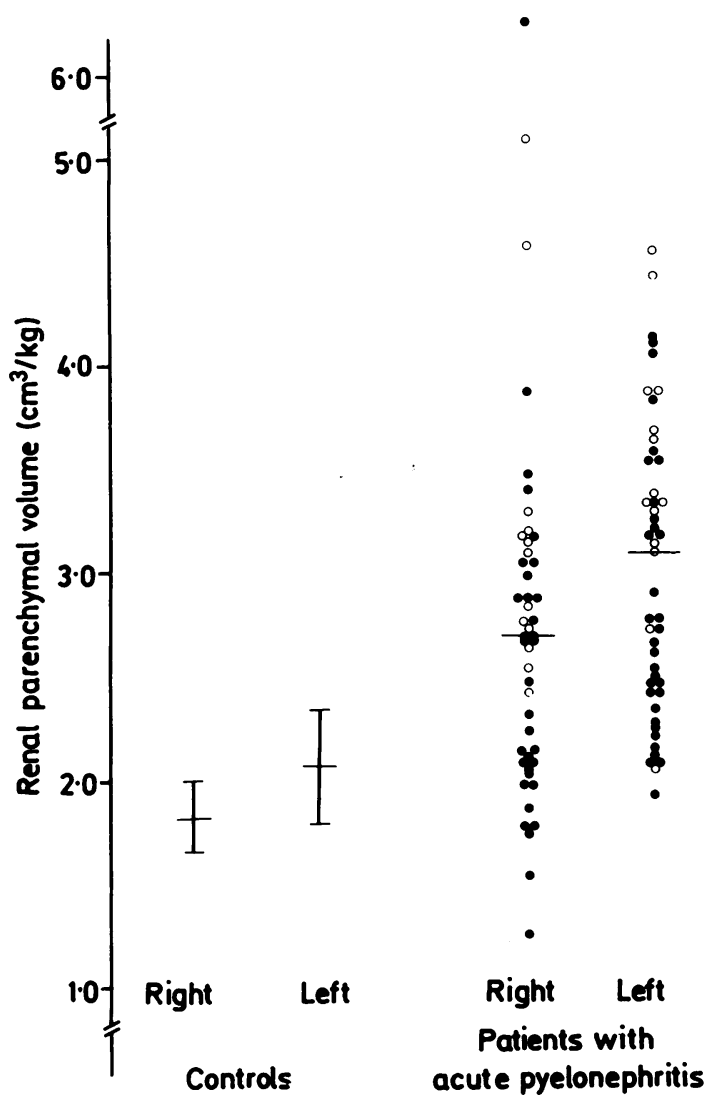

Fig 2 Renal parenchymal volume, expressed in $\mathrm{cm}^{3} / \mathrm{kg}$ body weight, of the right and left kidney in 47 children with acute pyelonephritis. Median values are indicated by straight lines. $\mathrm{O}=$ Children $\leqslant 2$ years; $\mathrm{O}=$ children $>2$ years of age. As a comparison the median values as well as the 25 th and 75 th percentiles of the right and left kidneys from 43 controls are given. ${ }^{16}$

body weight (range $1.25-6.26$ and $1.92-4.56 \mathrm{~cm}^{3} / \mathrm{kg}$, respectively). This was significantly higher than those of the control kidneys with a median value for the right kidney of 1.82 and for the left kidney of $2.07 \mathrm{~cm}^{3} / \mathrm{kg}$ body weight (mean (SD) $1.83(0.27)$ and $2 \cdot 10(0.34) \mathrm{cm}^{3} / \mathrm{kg}$, respectively). Thirty $(64 \%)$ of the right kidneys and $26(55 \%)$ of the left kidneys of patients with acute pyelonephritis were so enlarged that they were above $+2 \mathrm{SD}$ of the sizes in controls. To clarify whether there was an age difference in patients with more or less enlarged kidneys the 47 patients with acute pyelonephritis were stratified into three groups: (1) those with both renal parenchymal volumes $>+2$ SD of that of controls $(n=20)$; their median age was 1.3 years) (2) those with one renal parenchymal volume $>+2 \mathrm{SD}$ of that of controls $(n=18)$; their median age was 4.7 years; and (3) those with both renal parenchymal volumes $<+2$ SD of that of controls $(n=9)$; their median age was 8 years. The difference between group (1) and (2) and between (2) and (3) was significant: $p<0 \cdot 01$ and $p<0 \cdot 05$, respectively. In the youngest patients both kidneys were often enlarged $>+2 \mathrm{SD}$ while so pronounced an enlargement was less frequent in the older children.

Fig 3 shows changes in renal parenchymal volume from the first week to the third to sixth week in 30 patients studied on these two occasions. Patients are divided into those in whom both kidneys decreased $>0.3 \mathrm{~cm}^{3} / \mathrm{kg}$, assessed as bilateral acute pyelonephritis $(n=20)$ and those with only one kidney changing $>0.3 \mathrm{~cm}^{3} / \mathrm{kg}$, assessed as unilateral acute pyelonephritis $(n=10)$. The median decrease in the most affected kidney with bilateral acute pyelonephritis was $1.20 \mathrm{~cm}^{3} / \mathrm{kg}$ while that of the least affected kidney was $0.74 \mathrm{~cm}^{3} / \mathrm{kg}$. In those patients with an assumed unilateral acute pyelonephritis the median decrease was $0.70 \mathrm{~cm}^{3} / \mathrm{kg}$ and the mean decrease in volume of all affected kidneys was $0.87 \mathrm{~cm}^{3} / \mathrm{kg}$ body weight.

Fig $4 \mathrm{a}$ and $\mathrm{b}$ and the table show the changes in renal parenchymal volume of the right and left kidney of 32 patients during the first seven weeks after starting antibiotic treatment. The figures indicate the significant changes in renal parenchymal volume determined by the paired $t$ test. When all kidneys were compared (right+left), there was a significant decrease in renal parenchymal volume from the periods one to eight days to nine to 16 days $(\mathrm{p}<0.001$, paired $t$ test $)$. No significant change was found between the periods nine to 16 days and 17 to 24 days but there was a significant decrease between the period nine to 16 days and 25 to 32 days or 33 to 49 days $(\mathrm{p}<0.01$ and $\mathrm{p}<0.001$, respectively). No significant change was found between the periods 17 to 24 days, 25 to 32 days, and 33 to 49 days. When these last three periods were combined-that is, 17 to 49 days-there was a significant fall in renal parenchymal volume from nine to 16 days to 17 to 49 days (compared by the paired $t$ test). Thus the renal parenchymal volume decreased during the first three to four weeks after acute pyelonephritis; thereafter no significant change was seen.

\section{Discussion}

The most commonly described sonographic sign of acute pyelonephritis, except enlargement, is decreased echogenicity in the corticomedullary region. ${ }^{17-19}$ We could not confirm this by our method in conformity with Dinkel et $a l,{ }^{13}$ who consider sonolucency a variable sign, dependent on subjective judgment and therefore unreliable. We, 


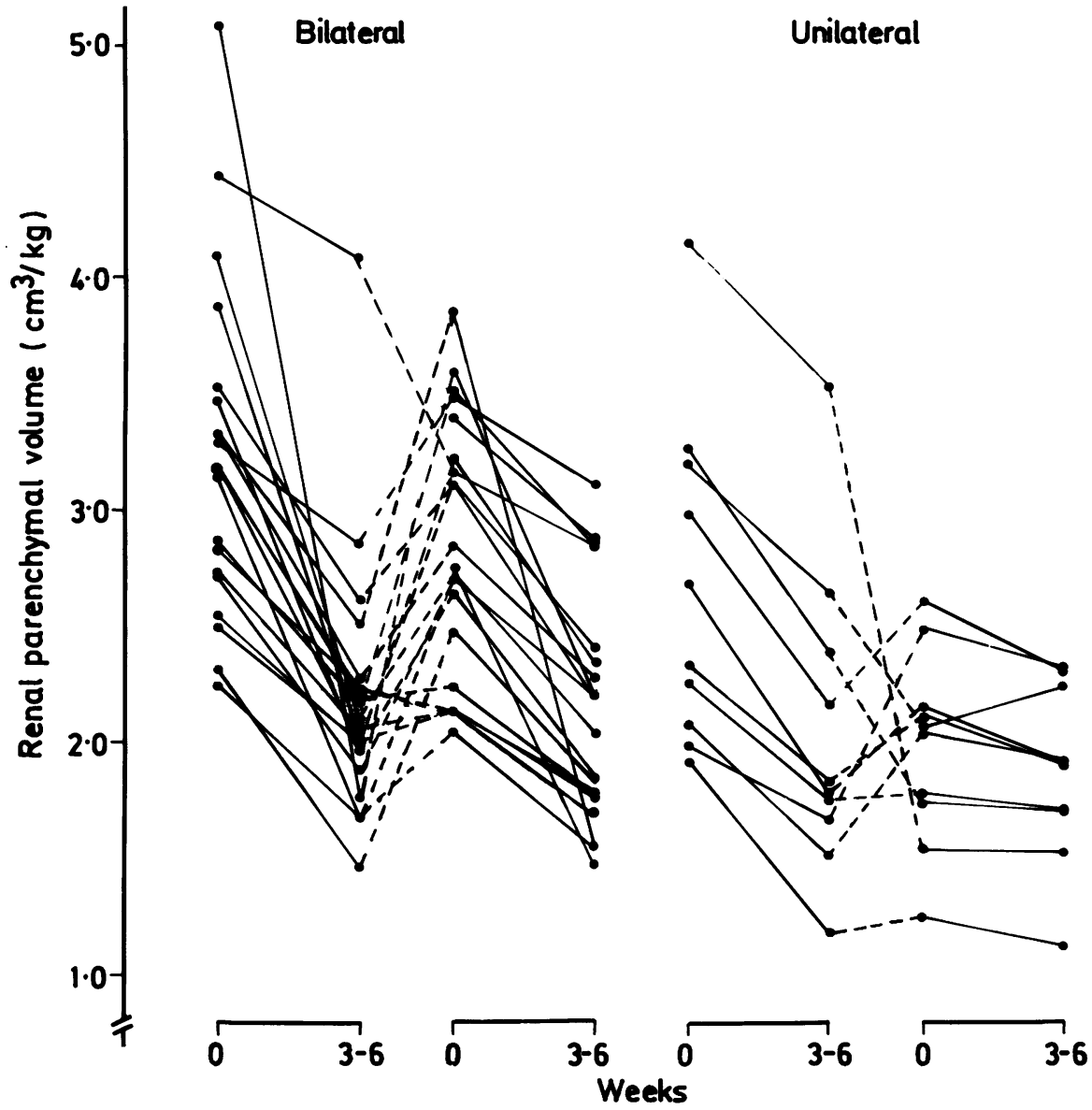

Fig 3 Renal parenchymal volume ( $\mathrm{cm}^{3} / \mathrm{kg}$ body weight) in 30 patients, examined during the first week acute pyelonephritis and three to six weeks after, and assessed as bilateral and unilateral acute pyelonephritis. The volume of the most affected kidney (that is, with the greatest change in renal parenchymal volume) is drawn to the left. The broken lines combine the two kidneys of each patient.

like them, found an increased kidney size. Their determination of kidney volume is based on formula for the ellipsoid using length, width, and depth, ${ }^{20}$ and is thus quite different from our stepped section method. Dinkel et al found in acute pyelonephritis an average kidney volume of $175 \%$ of normal, while we found a renal parenchymal volume of about $150 \%$. This difference might be explained by the different methods used. Dinkel et al include the renal pelvis in their measurements but they claim that the increased kidney volume is caused primarily by parenchymal thickening. Provided that the total kidney volume of Dinkel et al of $175 \%$ is a correct and reliable measurement, our calculation of the parenchymal volume as $150 \%$ must imply that the renal pelvis and the central high echogenic structures also increase in size during acute pyelonephritis. This is in accord with several authors who describe the dilated collecting system secondary to paralysis of the ureter as a consequence of bacterial endotoxins. ${ }^{821-23}$ Furthermore, we performed our ultrasound examinations as soon as possible but sometimes a delay of a few days was inevitable and treatment was started. The regression in kidney volume could have started then.

We have chosen to determine renal size by renal parenchymal volume instead of just measuring renal length. Volume measurements, if accurate, are more sensitive to changes in renal size than single measurements of length. A change in kidney size 

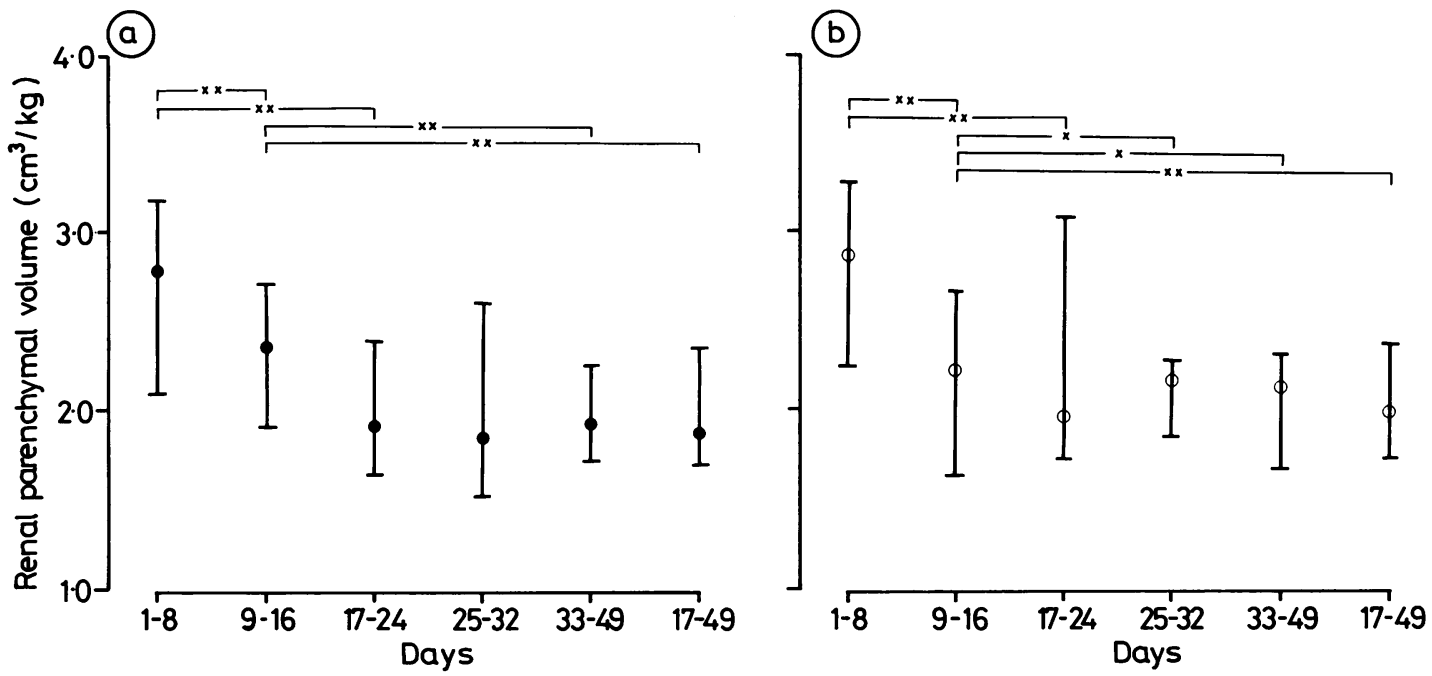

Fig 4a and b Median values of renal parenchymal volume as well as the 25th and 75th percentile of the right and the left kidney of 32 patients examined repeatedly. Significant changes, calculated by paired t test, are indicated in the figure $x=p<0.05, x x=p<0.01$. $=$ Right kidney $(a) ; O=$ left kidney $(b)$.

Table Mean and median renal parenchymal volumes of the two kidneys after different periods of time after acute pyelonephritis

\begin{tabular}{|c|c|c|c|c|c|c|}
\hline & \multicolumn{5}{|c|}{ Time after start of antibiotic treatment (days) } & \multirow{2}{*}{$\begin{array}{l}\text { Controls } \\
(n=43)\end{array}$} \\
\hline & $\begin{array}{l}1-8 \\
(n=30)\end{array}$ & $\begin{array}{l}9-16 \\
(n=18)\end{array}$ & $\begin{array}{l}17-24 \\
(n=16)\end{array}$ & $\begin{array}{l}25-32 \\
(n=12)\end{array}$ & $\begin{array}{l}33-49 \\
(n=18)\end{array}$ & \\
\hline \multicolumn{7}{|l|}{ Right kidney: } \\
\hline Mean & $2 \cdot 71$ & $2 \cdot 27$ & $2 \cdot 07$ & 1.98 & 2.05 & 1.83 \\
\hline Median & $2 \cdot 78$ & $2 \cdot 36$ & $1 \cdot 89$ & $1 \cdot 86$ & 1.94 & 1.82 \\
\hline \multicolumn{7}{|l|}{ Left kidney: } \\
\hline $\begin{array}{l}\text { Mean } \\
\text { Median }\end{array}$ & $\begin{array}{l}2.93 \\
2.92\end{array}$ & $\begin{array}{l}2 \cdot 30 \\
2 \cdot 28\end{array}$ & $\begin{array}{l}2.44 \\
2.03\end{array}$ & $\begin{array}{l}2 \cdot 25 \\
2 \cdot 24\end{array}$ & $\begin{array}{l}2 \cdot 11 \\
2 \cdot 21\end{array}$ & $\begin{array}{l}2 \cdot 10 \\
2.07\end{array}$ \\
\hline
\end{tabular}

that is reflected by a change in length of $12 \%$ can be suspected to be due to a methodological error. An increase in all diameters of the kidney by $12 \%$ is equivalent to an increase in volume of $40 \%$, which cannot be attributed to a methodological error.

The increased renal parenchymal volume found in this study might be due to oedema of the infected kidney according to Heptinstall, ${ }^{24}$ but it might also be caused by hyperaemia secondary to an increased renal plasma flow found in acute pyelonephritis. ${ }^{25}$ Whether or not the rapid decline in size seen during the first two weeks is caused by a regression of oedema or hyperaemia, or both, remains to be elucidated.

The most enlarged kidneys were found among the smallest children, which is in accord with Dinkel et al. ${ }^{13} \mathrm{We}$ also found that infants and small children had bilateral infections more often. This confirms a previous study performed in children with recurrent urinary tract infection after acute pyelonephritis in which we reported that only children having had their first infection with acute pyelonephritis before the age of 3 years had reduced glomerular filtration rates. ${ }^{26}$ This, we thought, was due to the fact that small children more often had bilateral infections with a poor capacity for compensatory hypertrophy in previously infected kidneys. ${ }^{26}$

The enlargement of the kidneys during the acute phase of the infection regressed within four weeks. The most prominent decrease in renal size was found during the first two weeks. No clear cut decrease was found from the second to the third 
week but there was one from the second to the fourth or fifth week. Dinkel et al concluded that there was a nearly complete normalisation of kidney volume after four to six days, but in their results they reported a reduction in kidney volume of $20-45 \%$ within six to eight days and of up to $60 \%$ within two weeks. ${ }^{13}$ It is somewhat difficult to determine from their presentation the exact time when the size of the kidney returned to normal.

In conclusion, the parenchymal volume in kidneys affected by acute pyelonephritis increases to around $150 \%$. This enlargement regresses within four to five weeks. We therefore suggest that the first examination for determination of renal size, urography, or ultrasonography after acute pyelonephritis should be performed after at least four to six weeks. An early ultrasonographic examination is recommended, however, to exclude obstructive uropathy as well as for level diagnosis of urinary tract infection as an enlarged kidney is a sign of upper urinary tract infection.

This study was supported by grants from the Karolinska Institute and the Swedish Medical Research Council (No 06864).

\section{References}

1 Winberg J, Bergström T, Jacobsson B. Morbidity, age and sex distribution, recurrences and renal scarring in symptomatic urinary tract infection in childhood. Kidney Int 1975;8:S101-6.

2 Smellie JM, Hodson CJ, Edwards D, Normand ICS. Clinical and radiological features of urinary infection in childhood. $\mathrm{Br}$ Med J 1964;ii:1222-6.

${ }^{3}$ Hodson CJ, Drewe JA, Karn MN, King A. Renal size in normal children. A radiographic study during life. Arch Dis Child 1962;37:616-22.

4 Hodson CJ, Wilson S. Natural history of chronic pyelonephritic scarring. Br Med J 1965;ii:191-4.

5 Wikstad I, Aperia A, Broberger O, Ekengren K. Vesicoureteric reflux and pyelonephritis. Long time effect on area of renal parenchyma. Acta Radiol JDiagn/ (Stockh) 1979;20:252-60.

6 Winberg J, Claesson I, Jacobsson B, Jodal U, Peterson H. Renal growth after acute pyelonephritis in childhood: An epidemiological approach. In: Hodson CJ, Kincaid Smith P, eds. Reflux nephropathy. New York: Masson Publishing, 1979:309-22.

${ }^{7}$ Kogan BA, Kay R, Wasnick R, Carty H. ${ }^{99 \mathrm{~m}} \mathrm{Tc}-\mathrm{DMSA}$ scanning to diagnose pyelonephritic scarring in children. Urology 1983;6:641.

${ }^{8}$ Little PJ, McPherson DR, de Wardener HE. The appearance of the intravenous pyelogram during and after acute pyelonephritis. Lancet $1065 ; \mathrm{i}: 1186-8$.
${ }^{9}$ Silver TM, Kass EJ, Thornbury JR, Konnack JW, Wolfman MG. The radiological spectrum of acute pyelonephritis in adults and adolescents. Radiology 1976;118:65-71.

${ }^{10}$ Morehouse HT, Weiner SN, Hoffman JC. Imaging in inflammatory disease of the kidney. $A J R$ 1984;143:135-41.

11 Bova JG, Potter JL, Arevalos E, Hopens T, Goldstein HM, Radwin HM. Renal and perirenal infection: the role of computerized tomography. J Urol 1985;133:375-8.

12 Johansson B, Troell S, Berg U. Urographic renal size in acute pyelonephritis in childhood. Acta Radiol [Diagn] (Stockh) 1988;29:155-8.

13 Dinkel E, Orth S, Dittrich M, Schulte-Wissermann H. Renal sonography in the differentiation of upper from lower urinary tract infection. AJR 1986;146:775-80.

14 Jodal U, Lindberg U, Lincoln K. Level diagnosis of symptomatic urinary tract infections in childhood. Acta Paediatr Scand 1975;64:201-8.

15 Troell S, Berg U, Johansson B, Wikstad I. Ultrasonographic renal parenchymal volume related to kidney function and renal parenchymal area in children with recurrent urinary tract infections and asymptomatic bacteriuria. Acta Radiol [Diagn] (Stockh) 1984;25:411-6.

16 Troell S, Berg U, Johansson B, Wikstad I. Renal parenchymal volume in children. Normal values assessed by ultrasonography. Acta Radiol [Diagn] (Stockh) 1988;29:127-31.

17 Rosenfield AT, Taylor KJW, Crade M, DeGraaf CS. Anatomy and pathology of the kidney by gray scale ultrasound. Radiology 1978;128:737-44.

18 Edell SL, Bonavita JA. The sonographic appearance of acute pyelonephritis. Radiology 1979;132:683-5.

19 Lee JKT, McClennan BL, Melson GL, Stanley RJ. Acute focal bacterial nephritis: Emphasis on gray scale sonography and computed tomography. AJR 1980;135:87-92.

${ }^{20}$ Hegedüs V. Three dimensional estimation of renal shape and volume at angiography. Acta Radiol [Diagn] (Stockh) 1972;12:87-99.

21 Roberts JA. Experimental pyelonephritis in the monkey. III. Pathophysiology of ureteral malfunction induced by bacteria. Investigative Urology 1975;13:117-20.

${ }^{22}$ King WW, Cox CE. Bacterial inhibition of ureteral smooth muscle contractility. I. The effect of common urinary pathogens and endotoxin in an in vitro system. $J$ Urol 1972;108:700-5.

${ }^{23}$ Hellström M, Jodal U, Mårild S, Wettergren B. Ureteral dilatation in children with febrile urinary tract infection or bacteriuria. AJR 1987;148:483-6.

${ }^{24}$ Heptinstall RH. Pyelonephritis. II. Pathological features. In: Heptinstall RH, ed. Pathology of the kidney. Boston: Little, Brown and Company, 1974:878.

${ }^{25}$ Berg U. Renal function in acute febrile urinary tract infection in children: Pathophysiologic aspects on the reduced concentration capacity. Kidney Int 1981;20:753-8.

${ }^{26}$ Berg U, Johansson B. Age as a main determinant of renal functional damage in urinary tract infection. Arch Dis Child 1983;58:963-9.

Correspondence to $\mathrm{Dr} U$ Berg, Department of Paediatrics, Huddinge Hospital, S-141 86 Huddinge, Sweden.

Accepted 30 March 1988 